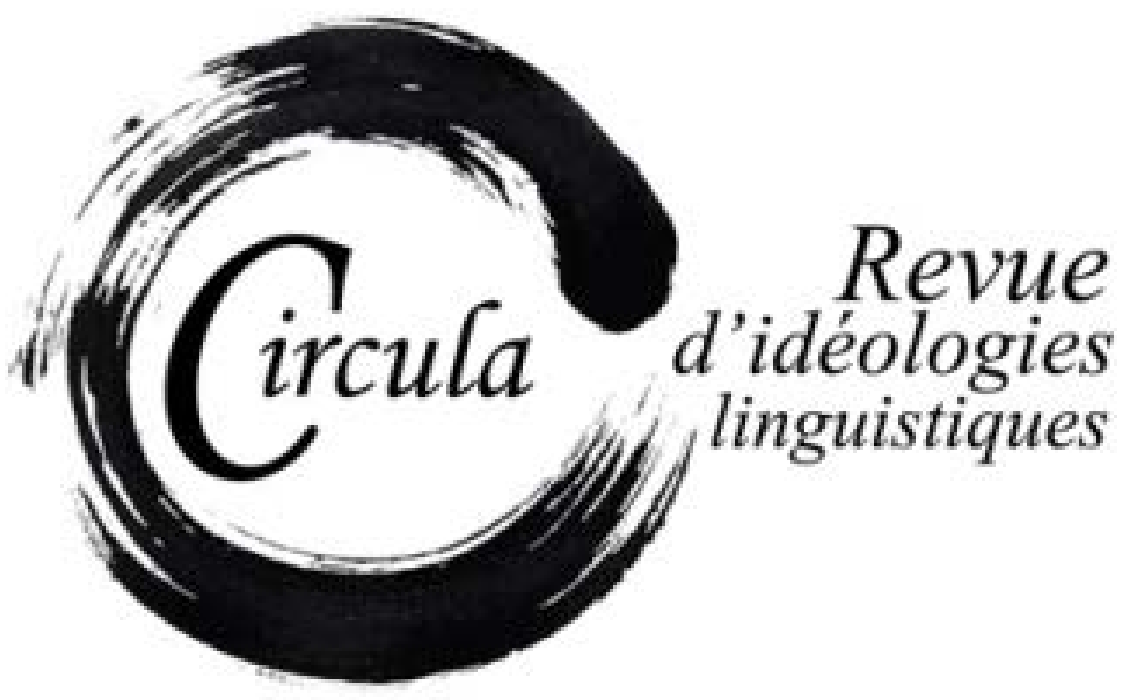

TITRE: De LA IDEOLOGíA DE LA(S) LENGUA(S) A LA(S) IDEOLOGÍA(S) DE LA LINGÜÍSTICA

Auteur(s): Pierre SWiggers, Katholieke Universiteit Leuven

Revue: CiRCula, numÉRO 8 - IDEOLOGÍAS EN OBRAS SOBRE LA LENGUA ESPAÑOLA (SS. XV-XX)

PAGES: $70-101$

ISSN: 2369-6761

Directeurs: : Francisco Escudero Paniagua, Carlos Villanueva García, Carmen Quijada Van DEN BERGHe, José Jesús GÓmez AsEnCIO

URI: HTTP://HDL.HANDLE.NET/11143/15552

DOI: HTTPS://DOI.ORG/10.17118/11143/15552 


\title{
De la ideología de la(s) lengua(s) a la(s) ideología(s) de la lingüística
}

\author{
Pierre Swiggers, Katholieke Universiteit Leuven \\ pierre.swiggers@kuleuven.be
}

siempre la lengua fue compañera del imperio

(Antonio de Lebrixa [Nebrija], Gramatica [... s sobre la lengua castellana, 1492, prólogo)

\begin{abstract}
Resumen: Esta contribución trata de ideología(s) lingüística(s) en su relación con las ideas y la praxis lingüísticas, con particular atención a la lingüística española e hispánica. Primero se formulan algunas reflexiones de índole metodológica y epistemológica acerca del concepto de 'ideología', antes de esbozar una tipología de ideologías lingüísticas; los distintos tipos vienen ilustrados con ejemplos tomados en varios periodos de la historia de la lingüística. Después se estudian tres aspectos de la(s) ideología(s) de la(s) lengua(s): procesos formativos, mecanismos de funcionamiento, y unidades descriptivas. A continuación se discuten las tareas que constituyen la agenda de investigación de procesos de ideología lingüística y sus reflejos (textuales). En conclusión se ofrecen algunas consideraciones acerca de la presencia 'inevitable’ de ideología(s), y acerca del impacto ideológico del factor (existencial) del tiempo.
\end{abstract}

Palabras clave: historia e historiografía de la lingüística; ideología(s) de la(s) lengua(s); lingüística española (hispánica); tipos de ideología lingüística

Abstract: This contribution deals with linguistic ideology in its relation to linguistic thought and praxis (with particular attention paid to the history of Spanish and Hispanic linguistics). Starting from methodological and epistemological reflections on the concept of 'ideology', a typology of language ideologies is outlined, and illustrated with a number of examples taken from different periods. Subsequently three aspects of language ideology/ideologies are dealt with: formative processes, operative mechanisms, and descriptive units. This is followed by a discussion of a comprehensive research agenda for the investigation of language-ideological processes and (textual) reflexes. The text is rounded off with considerations on the inescapable presence of ideology, and on the ideological impact of the existential dimension of time.

Key words: history and historiography of linguistics; ideology/-ies of language(s); Spanish (Hispanic) linguistics; types of linguistic ideology 


\section{Introducción'1: alrededor del concepto de ideología}

Aunque siendo una palabra "culta", el término ideología es uno de los más confusos, desde el punto de vista semántico². Este hecho se debe a dos fenómenos:

a) Un cambio radical de su significación originaria (que era bien delimitada);

b) Una extensión amplísima de su ámbito de aplicación.

Echemos un vistazo rápido a los dos fenómenos.

(a’) Creado en 1796 por Destutt de Tracy (en su Mémoire sur la faculté de penser), el término ideología sirvió para designar una ciencia: la del origen de las ideas y de las leyes de su desarrollo y funcionamiento. Se trataba de un estudio científico, neutro y no determinado por factores externos.

En el siglo XIX se produjo una conversión radical del semantismo del término: con la obra de Marx y de Engels, la ideología se convirtió en una construcción de opiniones, de convicciones (falsas), de prejuicios, esa construcción estando determinada por factores externos (socio-económicos, políticos), y sirviendo a los intereses de un grupo social.

(b’) Al inicio el término ideología designaba una ciencia bastante "exacta" (como la fisiología), después un sistema de ideas, y más tarde todo lo que es subyacente a sistemas de ideas: ideas políticas, religiosas, metafísicas, o científicas.

Estos fenómenos se reflejan en las informaciones que nos procuran los lexicógrafos. Si se consulta, por ejemplo, la entrada "idéologie" del Trésor de la langue française3, se pueden distinguir, un sentido con focalización "referencial” y varios sentidos más "centrífugos".

Esquematizando las informaciones, se obtiene lo siguiente:

1. Texto redactado y revisado a partir de la conferencia plenaria en las Primeras Jornadas de Ideologías en obras sobre la lengua española (Salamanca, 23-24 de noviembre 2017). Agradezco a los participantes sus comentarios, y quiero dar las gracias a Pepe Gómez Asencio (Salamanca), a Miguel Ángel Esparza Torres (Madrid), a Félix San Vicente (Bologna-Forli), a Herman Parret (Lovaina) y a Andy Peetermans (Lovaina) por ideas que me inspiraron.

2. Buenas introducciones al concepto de ideología son Larrain (1979) y Eagleton (1991).

3. Los sentidos que da el Trésor de la langue française, vol. 10, s.v. idéologie, son los siguientes: "science des idées [...], de leur nature, de leur rapport avec les signes qui les représentent, et surtout de leur origine"; "ensemble plus ou moins cohérent des idées, des croyances et des doctrines philosophiques, religieuses, politiques, économiques, sociales, propre à une époque, une société, une classe et qui oriente l'action"; "système d'idées, philosophie du monde et de la vie"; "(idéologie): dans la philos. marxiste, par opposition aux faits économiques, à la science et à l'infrastructure, seule déterminante"; "théorie sur quelque chose que l'on veut mettre en valeur"; "(idéologie): par opposition à la philosophie dont l'idéologie apparaît comme une vulgarisation"; "théorie vague et nébuleuse, portant sur des idées creuses et abstraites, sans rapport avec les faits réels"; "théorie sur quelque chose que l'on veut mettre en valeur". 
(A) Un término que en su origen tenía un sentido filosófico preciso ${ }^{4}$, con referencia a una corriente filosófica de finales del siglo XVIII e inicios del siglo XIX; esta corriente fue marginalizada por Napoleón y fue criticada a lo largo del siglo XIX (por ejemplo por Maine de Biran)

(B) Un abanico de sentidos menos precisos:

- $\quad$ "conjunto de ideas y convicciones filosóficas, religiosas, sociales, políticas, dentro de una constelación temporal"

- $\quad$ "superestructura intelectual" (muy a menudo utopista) ${ }^{6}$

- "discurso propagandista" (v. la expresión ideología del progreso)

- " "filosofía de vulgarización"

- " teoría nebulosa, confusa".

Estos sentidos menos precisos se dejan sintetizar, más o menos adecuadamente, bajo un concepto generalizador de "conjunto (más o menos sistemático) de interpretación global””.

También es importante observar que las ideologías pueden establecer fronteras entre disciplinas: Gal y Irvine (1995), por ejemplo, tratan de este fenómeno en relación con las ciencias sociales.

Resumiendo, a largos trazos, el recorrido histórico: de concepto "absoluto", ideología se desarrolló hacia un concepto "relativo": ideología de (algo).

Es también ese concepto "relativo" de ideología lo que es central en estas "Primeras Jornadas de Ideologías en obras sobre la lengua española”, dedicadas a la ideología de la lengua; un concepto relativo que cabe precisar, porque también el complemento "de la lengua" necesita una precisión: ¿se trata de ideología de la lengua, de ideología (invertida) en la lengua, de ideología (adoptada) delante de la lengua, o de ideología (en la reflexión) sobre la lengua? Vale la pena profundizar en este asunto.

\section{2. "Ideología lingüística": un campo vasto}

Para hacerlo, me parece útil partir de un concepto, captado bajo un sintagma nominal, que no contiene un complemento, sino un adjetivo calificativo: ideología lingüística.

4. Se trata pues de un nombre propio que se refiere a la corriente que en francés se designa como la Idéologie.

5. Son sentidos que se han desarrollado en obras como las de Marx, Gramsci, Mannheim, Althusser, Kristeva.

6. Véase el título de la obra clásica de Mannheim (1953).

7. Véase la definición de la Encyclopaedia universalis (Paris, 1968-74), vol. 9, s.v. idéologie: "L'idéologie est un système global d'interprétation du monde historico-politique". 
Propongo el término de ideología lingüística para que se pueda, por un lado, circunscribir un campo de estudio que no se presenta como una evidencia, ni tampoco como una división disciplinal tradicional, y para que se puedan, por otro lado, colocar ciertos tipos de estudio.

Primero parece útil indicar los campos de estudio a partir de los cuales se han estudiado fenómenos de ideología lingüística. Se pueden distinguir por lo menos cinco:

1. La antropología (v. Asad, 1979), especialmente la antropología lingüística, y más en particular en una de sus ramas, la etnografía de la comunicación o etnografía del hablar (ethnography of communication/ethnography of speaking; véanse las contribuciones en Gumperz y Hymes, 1972; Bauman y Sherzer, 1974);

2. La sociolingüística y la sociología del lenguaje, a veces con fuerte vinculación a la antropología lingüística (v. el manual de Hymes, 1974, que desarrolla una teoría de la sociolingüística en clave antropológica);

3. La semiótica social (v. Errington, 1988): en este terreno de estudios, la importancia de la ideología ha sido enfatizada bajo la influencia de Bourdieu y de Greimas;

4. La historiografía de la lingüística, especialmente la historia de ciertos tipos de praxis lingüísticas, como la estandarización de lenguas (v. Joseph, 1987), la lingüística misionera, la "modernización" (revolucionaria) de una lengua, etc.;

5. La filosofía y la epistemología de la lingüística: aquí cabe mencionar, aparte de la influencia de la semiótica, la de la filosofía posestructuralista (con autores como Foucault y Derrida).

Hay que resaltar el hecho de que es justamente dentro de la tradición de investigación socio-antropológica que la focalización sobre "ideología lingüística" (ingl. language ideology/ideologies) ha dado lugar a algunos trabajos fundamentales en los años 1970, con los artículos de Geertz (1973), sobre ideología como sistema cultural, y de Silverstein (1979), sobre el enlace entre estructuración lingüística y modelización ideológica.

En los años 1990 este interés se ha concretizado en unos volúmenes colaborativos (Schieffelin, Woolard y Kroskrity, 1998; Kroskrity, 2000) y en dos trabajos que presentan una visión panorámica de los estudios (Woolard y Schieffelin, 1994; Woolard, 1998).

Es dentro de este tipo de aproximación socio-antropológica que se han propuesto algunas definiciones de "ideología de la lengua/ideología lingüística"; cabe notar que Silverstein (1979) utiliza el término linguistic ideology, Friedrich (1989: 306) habla de "linguacultural ideology", mientras que autores como Irvine (1989), Woolard (1998,) Woolard y Schieffelin (1994) y Kroskrity (1992, 2000, 2004) utilizan el término language ideology o language ideologies ${ }^{8}$. ¿Ahora bien, qué se entiende bajo estos términos?

8. O: ideologies of language; $v$. Joseph y Taylor (1990). 
Silverstein (1979) define la ideología lingüística como un conjunto de ideas y convicciones que constituyen una racionalización y justificación de estructuras y usos de la lengua, en la percepción de los hablantes ("sets of beliefs about language articulated by users as rationalization or justification of perceived language structure and use").

Irvine (1989) define la ideología de la lengua como el sistema cultural de ideas, cargadas de intereses políticos y morales, acerca de relaciones sociales y lingüísticas ("the cultural system of ideas about social and linguistic relationships, together with their loading of moral and political interests").

Según Woolard (1998), se trata de representaciones, explícitas o implícitas, que constituyen la intersección entre seres humanos y lenguaje dentro de un universo social ("representations, whether explicit or implicit, that construe the intersection of language and human beings in a social world").

Kroskrity (2000) abarca el concepto de ideología(s) lingüística(s) como un enjambre, un cluster concept, caracterizado por cuatro propiedades:

- Las ideologías representan la percepción de la lengua y del discurso que conviene a los intereses de un grupo sociocultural particular;

- Las ideologías son múltiples (eso, en relación con las distinciones sociales entre grupos socioculturales con sus divergentes visiones);

- Las ideologías lingüísticas son "compartimentadas" (se sitúan en "sitios" específicos);

- Las ideologías son una mediación entre estructuras sociales y formas de hablar (forms of talk $)^{10}$.

Si intentamos definir, a partir de un examen más largo de estudios de ideología(s) lingüística(s) (llevados a cabo dentro de los cinco campos ya mencionados) el concepto de "ideología lingüística", me parece que se puede cristalizar un "perfil" de la ideología lingüística a partir de 5 rasgos (v. Woolard, 1998):

- Se trata de un fenómeno de representación / percepción afectiva y subjetiva ${ }^{11}$, que existe a nivel colectivo, aunque no siempre está compartido completamente dentro de una comunidad (v. Gal y Woolard, 1995);

- La ideología se acompaña de un intento de racionalización, aunque no se puede justificar de manera meramente lógica; por eso, las ideologías siempre usan de estrategias retóricas (v. sección 7);

9. Kroskrity $(2000,7)$ : "Language ideologies are profitably conceived as multiple because of the multiplicity of meaningful social distinctions (class/gender/clan), within sociocultural groups that have the potential to produce divergent perspectives expressed as indices of group membership".

10. De hecho, cabe distinguir entre discursos secundarios y discursos terceros con respecto a usos (y comportamientos) lingüísticos; cf. Bloomfield (1944).

11. Acerca de la percepción 'desde fuera', véase Flaitz (1988). 
- La ideología lingüística supone una distinción entre lenguas (o variedades / registros) y entre grupos, y supone un contexto cultural y/o político de diferenciación (v. Gal y Irvine, 1995) $)^{12}$

- La ideología lingüística siempre tiene que ver con relaciones de "fuerza" (v. Véron, 1978; Fabian, 1986; Errington, 2007): se trata de poder y/o de prestigio;

- La ideología lingüística implica, en cierta medida, una manipulación (de datos, de ideas, de personas), y se acompaña de procesos de promoción, de represión, o marginalización.

\section{Los "niveles" de ideología}

Hasta ahora hemos utilizado el concepto abarcador de "ideología lingüística”. Cabe preguntar si es posible dar una articulación más organizada a este concepto. Me parece que hay que distinguir tres macro-planos:

(1) Ideología del lenguaje: aquí se trataría de lo que "se dice y se cree" sobre el lenguaje, por ejemplo como instrumento de engaño (= la visión de Platón acerca del lenguaje; v. Derbolav, 1972), como "espejo" de la aprehensión de la realidad (= la concepción de la gramática especulativa; v. Bursill-Hall, 1971; Rosier, 1983), como instrumento de análisis del pensamiento (lo que fue la aproximación general del lenguaje en el siglo XVIII; v. Juliard 1970) o como expresión de una visión del mundo (v. la filosofía del lenguaje de Humboldt; v. Borsche, 1981). De manera global, la ideología del lenguaje concierne a la relación entre el lenguaje, la "identidad"13 del individuo, de la sociedad y cultura, y la percepción de la realidad.

(2) Ideología de la lengua/una lengua: aquí se colocan las ideologías acerca del genio de tal o cual lengua/grupo de lenguas, o acerca de las "propiedades" de una lengua (como: dignidad; seriedad/ frivolidad; gracia).

A propósito de esta noción de "ideología de la lengua”, cabe distinguir entre dos niveles: la ideología de características de lenguas (como claridad, seriedad, riqueza), y la ideología de ciertos usos de la lengua (v. la ideología del buen uso [véase infra]; la ideología del habla politícamente correcta).

(3) Ideología de la lingüística: aquí tocamos aspectos de ideología científica, que tienen que ver con las normas (y convicciones) de cientificidad, de innovación, de modelización sistemática, etc.

12. En general se trata de una diferenciación por valoración positiva vs. negativa (donde se mezclan varios tipos de apreciación); cf. Trudgill y Giles (1978), Giles y Niedzielski (1998).

13. Acerca de la relación entre ideología, lengua, e identidad, véanse McQuown (1984), Gal (1993), Hassler (2011). De hecho, la construcción identitaria -en estrecha relación con la vinculación a una lengua- siempre conlleva una dimensión ideológica (v. las contribuciones en Gumperz, 1982). Los discursos "reflexivos" acerca de la construcción identitaria explicitan esa dimensión, pero muy a menudo aportan una carga ideológica adicional. 
Dentro de cada macro-plano, hay que distinguir (por lo menos es relevante por los macro-planos 2 y 3) entre actitudes y actividades ideológicamente marcadas, aunque hay que reconocer que las dos están muy a menudo conectadas.

\section{Siete tipos y ejemplos de "ideología(s) de la lengua"}

A continuación, presentamos una tipología de ideologías de la lengua/de una lengua (= el macro-plano (2) en el apartado 3); cabe señalar de antemano que los tipos que vendrán distinguidos pueden mezclarse en los textos fuente y que tanto la presencia de un tipo como las combinaciones de varios tipos se presentan en grados diferentes. Hablando de presencia, es útil distinguir entre presencia explícita y presencia implícita de aspectos ideológicos; la historia de la enseñanza de lenguas, por ejemplo, es un terreno en el cual ideologías implícitas y explícitas han sido, y siguen siendo, operativas (v. Swiggers, 2010a) ${ }^{14}$.

Con la siguiente tipología de ideologías - que desde la exigencia de la "neutralidad" del discurso científico se pueden considerar como "pecados" -, no pretendo presentar un elenco exhaustivo; lo importante es que hallemos aquí "tipos" que se conectan con aspectos distintos de la realidad fenomenológica y experiencial que es una lengua. Los ejemplos que ilustran cada uno de los tipos son tomados de la historia de la lingüística española, francesa, o europea en general.

(1) Ideología de la lengua "territorial" o "regional": aquí se trata de una ideología que se fundamenta en la concepción de la lengua como vinculada de manera intrínseca con su territorio "original". Como ejemplo ilustrativo he escogido la introducción de una obra anónima, publicada en Lovaina en 155915, la Gramatica dela Lengua Vulgar de España: esta obrita propone una descripción de la "lengua vulgar" del país, que el autor distingue de otras tres (el vasco, el árabe, el catalán). No estando de acuerdo con la denominación de "castellano" o "español", el autor defiende la designación como "lengua vulgar", y la conecta con sus orígenes en León y Aragón:

A esta, que io nombro Vulgar, algunos la llamaron lengua Española, en lo qual, a mi parescer, erraron, pues vemos que en España hai mas de una lengua; i otras mas antiguas, que no es esta, i de mas lustre, por los mas escritores que han tenido. Otros la llamaron Castellana, dandole el nombre dela provincia de Castilla, donde (segun se dize) ella mas floresce; loqual, aunque no paresce desaforado, todavía es nombre ambicioso, illeno de imbidia, pues es mas claro que la luz del sol, que los reinos de León, y Aragón tienen maior y mejor derecho enla lengua Vulgar, que no el reino de Castilla, i esto por tres razones: la primera, porque estando Castilla debaxo la sujecion de reies Moros, do no se hablava sino en Aravigo, en Aragon [sic], i Leon reinavan reies Cristianos, en cuio reino entonces ia se hablava en la lengua que ellos

14. Por supuesto, las observaciones de matización tienen sus consecuencias para el estudio de los procesos y mecanismos de las ideologías (v. sección 5), así como para la agenda de investigación (v. sección 6).

15. Sobre esta gramática, véase Cruz Casáñez y Swiggers (2015). 
quieren nombrar Castellana: la segunda, porque toda Castilla fue conquistada i reduzida ala lei de Cristo por la industria emparo, i favor delos reies de León i Aragón, echando della los Moros, que la posseïan: la tercera, por quanto siendo los dos reinos sobredichos con ceptro i real corona adornados, Castilla era condado sujeto i dando parias al reino de Leon (Gramatica dela Lengua Vulgar de España, 1559: a iijr-v)

(2) Ideología lingüístico-cultural europea, de índole religiosa: es el tipo de ideología que muy a menudo encontramos en las obras de los "lingüistas misioneros" ${ }^{16}$ defendiendo la superioridad de una lengua/las lenguas y de la cultura europeas ${ }^{17}$. Cabe notar que en algunos autores el discurso de superioridad se matiza con una pincelada de "contra-ideología", como es el caso en el prólogo de la gramática quechua de Fray Domingo de Santo Tomás, donde se destaca la no barbaridad de la lengua india.

Mi intento pues principal S.M. ofresceros este Artezillo ha sido, para que por el veays, muy clara y manifiestamente, quan falso es lo que muchos os han querido persuadir, ser los naturales delos reynos del Peru barbaros, \& indignos de ser tractados con la suauidad y libertad que los demas vassallos vuestros lo son. Lo qual claramente conoscera V.M. ser falso, si viere por este Arte, la gran policia que esta lengua tiene. La abundancia de vocablos, La conueniencia que tienen con las cosas que significan. Las maneras diuersas y curiosas de hablar. El suaue y buen sonido el oydo dela pronunciacion dessa, La facilitad para escriuirse con nuestros caracteres y letras: Quan facil y dulce sea a la pronunciacion de nuestra lengua, El estar ordenada y adornada con propriedad de declinacion, y demas propriedades del nombre, modos, tiempos, y personas del verbo. Y breuemente en muchas cosas y maneras de hablar, tan conforme ala latina, y española: y enel arte y artificio della, que no paresce sino que fue vn pronostico, que Españoles la auian de posseer. Lengua pues S.M., tan polida y abundante, regulada y encerrada debaxo delas reglas y preceptos dela latina como es esta (como consta por este Arte) no barbara, que quiere dezir (segun Quintiliano, y los demas latinos) llena de barbarismos y de defectos, sin modos, tiempos, ni casos, ni orden, ni regla, ni concierto, sino muy polida y delicada se puede llamar. Y si la lengua lo es, la gente que vsa della, no entre barbara, sino con la de mucha policia la podemos contar: pues segun el Philosopho en muchos lugares, no ay cosa en que mas se conozca el ingenio del hombre, que en la palabra y lenguaje que vsa, que es el parto delos conceptos del entendimiento. [...] (Domingo de Santo Tomás, Grammatica o Arte de la lengua general de los Indios de los Reynos del Perú, 1560)

(3) Ideología de la lengua de índole "social". Con este tipo de ideología de la lengua entramos en el campo de las discusiones acerca del "buen/mejor uso", un tema de mayor relevancia en la sociedad

16. Acerca de la ideología vehiculada por la lingüística misionera, véanse los trabajos de Esparza Torres (por ejemplo, 2005, 2014, 2015, 2016).

17. Aunque hay que resaltar que el discurso de los lingüistas misioneros no siempre es un discurso "imperalista" y de "superioridad"; v. Esparza Torres (2005, 2015). 
europea de la Edad Moderna. En el siglo XVI se discutía mucho acerca del mejor modelo de lengua (nacional) y acerca de los distintos usos: el uso de los $\operatorname{cortesanos}^{18}$, el uso de los cuerpos políticos y jurídicos ${ }^{19}$, el uso de los eruditos ("sabios"), y el uso popular ${ }^{20}$. Esta discusión muy a menudo acabó por distinguir, de manera "maniquea", entre buen uso y mal uso ${ }^{21}$; bastará recordar la célebre formulación de Vaugelas:

Il y a sans doute deux sortes d'Usages, un bon et un mauvais. Le mauvais se forme du plus grand nombre de personnes, qui presque en toutes choses n'est pas le meilleur, et le bon au contraire est composé non pas de la pluralité, mais de l'élite des voix, et c'est véritablement celuy que l'on nomme le Maistre des langues, celuy qu'il faut suivre pour bien parler, et pour bien escrire en toutes sortes de stiles, si vous en exceptez le satyrique, le comique, en sa propre et ancienne signification, et le burlesque, qui sont d'aussi peu d'estenduë que peu de gens s'y adonnent. Voicy donc comme on definit le bon Usage. C'est la façon de parler de plus saine partie de la Cour, conformément à la façon d'escrire de la plus saine partie des Autheurs du temps. Quand je dis la Cour, j'y comprens les femmes comme les hommes, et plusieurs personnes de la ville où le Prince reside, qui par la communication qu'elles ont avec les gens de la Cour participent à sa politesse. [...] Toutefois quelque avantage que nous donnions à la Cour, elle n'est pas suffisante toute seule de servir de reigle, il faut que la Cour et les bons Autheurs y concourent, et ce n'est que de cette conformité qui se trouve entre les deux, que I'Usage s'establit (Claude Favre de Vaugelas, Remarques sur la langue Françoise, 1647).

(4) Ideología de la lengua "nativista", en clave "xenófoba": es el tipo de ideología (relacionado al primer tipo) que se desarrolla cuando la lengua del territorio está amenazada por una lengua de "intrusión". Un ejemplo muy llamativo en la historia de la lingüística es una obra de Henri Estienne (Deux Dialogues du nouveau langage François, italianizé, \& autrement desguizé, 1578) en la cual criticó de manera vigorosa la invasión de palabras y expresiones italianas en la lengua francesa durante los reinos de Enrique II y Enrique III22. En su obra, que se presenta como un diálogo entre dos protagonistas, Philausone (defensor del italiano) y Celtophile (defensor del francés), y un árbitro, Philalèthe (bajo esta figura del "amigo de la verdad" se esconde el propio Estienne), el autor se propone enseñar cómo la lengua francesa está corrompiéndose por la mala influencia del italiano.

18. Un uso criticado por Pedro de Navarra en sus Dialogos de la differencia del hablar al escrivir (1590).

19. Un uso recomendado por Robert Estienne en su Grammaire Françoise (1557).

20. V. Pierre de la Ramée, Grammaire (1572): "Bref selon le iugement de Platon, Varron, Ciceron le peuple est souuerain seigneur de sa langue, \& la tient comme vn fief de franc aleu, \& nen doit recognoissance a aulcun seigneur. Lescolle de ceste doctrine nest point es auditoires des professeurs Hebreus, Grecs, \& Latins en luniuersite de Paris comme pensent ces beaux Etymologiseurs, elle est au Louure, au Palais, aux Halles, en Greue, a la place Maubert: Ainsi Ciceron a declaire quil sest reserue la science, mais touchant lusaige, quil la donne au peuple" (1572: 30).

21. O literate vs. illiterate speech; cf. Bloomfield (1927).

22. Acerca de la lucha de autores franceses contra los italianismos en el siglo XVI, véanse Picot (1906-1907), Sozzi (1972) y Swiggers (2003). 
[PHILALÈTHE.] Mais au contraire, qui est celui qui ne mette cela en doute? ou plutôt, qui ne le vous nie tout à plat? j'entends s'il est du nombre de ceux qui savent que c'est aujourd'hui d'une cour de France. Car (laissant les autres choses en quoi elle est différente de celle qui a été il y a vingt ou trente ans) s'il n'y avoit non plus d'étrangers, et nommément d'Italiens, qu'auparavant, il sembleroit que son autorité ne devroit diminuer quant à l'usage de la langue françoise: mais vous savez que pour quarante ou cinquante italiens qu'on y voyoit autrefois, maintenant on y voit une petite Italie (Henri Estienne, Deux Dialogues du nouveau langage François, italianizé, \& autrement desguizé, principalement entre les courtisans de ce temps: De plusieurs nouveautez, qui ont accompagné ceste nouveauté de langage: De quelques courtisanismes modernes, De quelques singularitez courtisanesques, 1578)

(5) Ideología de la lengua "nativista”. Este tipo de ideología, similar al tipo precedente pero (en principio) menos polémico, es el que encontramos en obras lingüísticas que alaban la lengua materna ${ }^{23}$ y que desarrollan un discurso acerca de las "cualidades" de la lengua (como: seriedad, gracia y riqueza). El mismo Henri Estienne hizo seguir a su libro de 1578 otro (publicado el año después) sobre la "precelencia" del francés (Proiect du livre intitulé De la precellence du langage François), poniendo de relieve la gracia y la riqueza de la lengua francesa y apuntando las "deudas" de otras lenguas con respecto al francés ${ }^{24}$. Este tipo de discurso dio lugar a descripciones muy imaginativas y subjetivas de la lengua nativa, como por ejemplo en la obra del jesuita Dominique Bouhours, quien comparó el francés con un río maravilloso, majestuoso y mesurado:

L'Espagnol, à mon avis, ressemble à ces fleuves, dont les eaux sont toûjours grosses \& agitées: qui ne demeurent gueres renfermez dans leur lict; qui se débordent souvent, \& dont les débordemens font un grand bruit, \& un grand fracas. L'italien est semblable à ces ruisseaux, qui gazouillent agreablement parmi les cailloux; qui serpentent dans des praires pleines de fleurs; qui s'enflent neanmoins quelquefois, jusqu'à inonder toute la campagne. Mais la langue Françoise est comme ces belles rivieres, qui enrichissent tous les lieux par où elles passent; qui sans estre ni lentes, ni rapides roullent majestueusement leurs eaux, \& ont un cours toûjours égal [...] Ainsi pour ne parler que de leurs genies, sans rien decider de leur naissance, il me semble que la langue Espagnole est une orgueilleuse qui le porte haut; qui se pique de grandeur; qui aime le faste, \& l'excès en toutes choses. La langue Italienne est une coquette toûjours parée \& toûjours fardée, qui ne cherche qu'à plaire, \& qui ne se plaist qu'à la bagatelle. La langue Françoise est une prude; mais une prude agreable, qui toute sage \& toute modeste qu'elle est, n'a rien de rude ni de farouche. C'est une fille qui a beaucoup de traits de sa mere, je veux dire de la langue Latine. [...] Pour peu qu'on les examine toutes deux, on verra qu'elles ont le mesme genie \& le mesme goust; \& que rien ne leur plaist tant

23. La corriente de "alabanzas" de la lengua nacional arranca y se desarrolla en el siglo XVI, como se puede desprender del elenco presentado en el Apéndice 1.

24. Para un análisis pormenorizado, cf. Swiggers (1997b, 2009). El contexto de valoración político-cultural ha sido estudiado por Gerighausen (1963). 
qu'un discours noble, \& poli, mais pur, simple, naturel, \& raisonnable. (Dominique Bouhours, Les Entretiens d'Ariste et d'Eugène, 1671)

Este tipo de ideología de la lengua nativa lo encontramos también, pero en clave "pre-comparatista" (v. Swiggers, 2017), en los intentos de "genealogía lingüística" con orientación "patriótica": así, en los siglos XVI y XVII (a veces, también en los siglos posteriores) se produjeron obras de "reconstrucción" de la historia lingüística de Europa, en las cuales el hebreo fue sustituido en su papel de lengua-madre por la lengua materna del autor (el flamenco, el "celto-belga”, el bretón, el sueco... .25.

(6) Ideología de la lengua sociopolítica, a nivel "nacional": es el tipo de ideología más estrechamente vinculado a acontecimientos políticos. Un periodo que nos ofrece una amplia cosecha de ejemplos es el de la Revolución francesa ${ }^{26}$ : durante aquella época, especialmente en los años 1789-1800, vieron la luz numerosos diccionarios de coloración ideológica²7.

1790. [Chantreau] Dictionnaire national et anecdotique.

1790. [Gallais] Extrait d'un dictionnaire inutile.

1790. Nouveau dictionnaire composé par un aristocrate.

1790. [Buée] Nouveau dictionnaire, pour servir à l'intelligence des termes mis en vogue par la révolution.

1794. Rodoni, Dictionnaire républicain et révolutionnaire.

1795. Synonymes jacobites.

1796. [Reinhard ?] Le Néologiste français ou Vocabulaire portatif des mots les plus nouveaux.

1799. Tenesson, Dictionnaire sur le nouveau droit civil.

1799. Wörterbuch der französischen Revolutions-Sprache.

1800. Cousin, Dictionnaire néologique des hommes et des choses.

1800-1801. Mercier, Néologie ou Vocabulaire de mots nouveaux.

Según las diferentes convicciones de los autores -sean estos defensores del Ancien Régime o seguidores de las ideas revolucionarias- hallamos aquí visiones opuestas de la realidad política y socio-económica cambiada y cambiante. Basta comparar los artículos Journal y Journaux en dos diccionarios, uno de un autor (Chantreau) que aplaude a los cambios políticos y sociales, y otro de un autor (Gallais), que deplora la "nueva moda".

25. Acerca de los trabajos de "genealogía lingüística" en los siglos XVI y XVII, véanse los estudios de Droixhe (1978) y de Van Hal (2010).

26. La ideología "revolucionaria" no solamente se refleja en la producción lexicográfica, sino también en las obras gramaticales de finales del siglo XVIII; v. Swiggers (1997c).

27. Para un análisis de algunos diccionarios de la época revolucionaria, v. Desmet, Roorycky Swiggers (1990) y Swiggers (2011). 
Dans l'ancien régime c'étoit une feuille périodique, qui parloit de la pluie et du beau tems, donnoit des extraits de catalogues de librairie, et quelques lettres de MM. les abonnés à M. le rédacteur, que dans les cafés on prenoit bonnement pour des lettres. Par la voie de ces feuilles on étoit informé très-exactement du genre et du nombre de grimaces que telle ou telle actrice avoit faites dans une pièce nouvelle [...] Mais que tout est changé ! Ces feuilles, autrefois la pâture de nos désoeuvrés, sont à présent l'aliment de toutes les classes de citoyens. On court après, on se les arrache, on les dévore. Nos politiques y lisent la régénération de l'empire et y trouvent les hausses et les baisses de l'aristocratie. Les muses sont réduites au silence, le journaliste seul est en scène où il a le plus grand succès. (Chantreau, Dictionnaire national et anecdotique, 1790, art. Journal)

Une armée de journalistes est sortie tout à coup du sein de la révolution, comme cette foule d'insectes venimeux ou incommodes sortent en été au sein des marais fangeux. [...] J'oserai dire que les vrais ennemis de la France et de la révolution sont ces écrivains énergumènes, qui, depuis un an, ne cessent de sonner l'alarme, de caresser le peuple et de flagorner le côté gauche de l'Assemblée. (Gallais, Extrait d'un dictionnaire inutile, 1790, art. Journaux)

Es interesante observar que algunos de estos diccionarios no solamente ventilan, a través de sus entradas, convicciones ideológicas, sino que también construyen un discurso metalexicográfico ${ }^{28}$ en relación con la carga ideológica de las palabras:

On pourrait ranger les mots [...] en trois classes, savoir: les mots absolument neufs et qui n’avaient jamais frappé les oreilles, avant la Révolution [...] Secondement les mots, déjà connus et usités, mais employés aujourd'hui dans une significaton nouvelle ou plus étendue. Et enfin les expressions demi-gauloises et tombées en désuétude, qu'on a pour ainsi dire rajeunies et portées à la hauteur de la Révolution, que leurs créateurs ne soupçonnaient guères, lors de la première création. (Le Néologiste français ou Vocabulaire portatif des mots les plus nouveaux, 1796, prólogo).

(7) Ideología de la lengua político-religiosa, a nivel transnacional: este tipo, similar al tipo que encontramos en la lingüística misionera, aunque en aquel caso se trata de un posicionamiento ideológico 'intercontinental' y 'transétnico', se caracteriza por la alabanza, y defensa, de una lengua en un contexto de enfrentamiento político y/o religioso. Me limito a dar dos ejemplos, tomados de la historia de la gramaticografía española en el siglo XVII.

A inicios del siglo XVII, un maestro de lenguas alemán, activo en Colonia, Heinrich Doergang(k), publicó una gramática del español. Defensor ardiente de la religión católica, Doergang(k) alaba a la gens Hispanica, tan constante y aplicada en la observación de la fe y de la moral católicas. La

28. Un discurso que moviliza una terminología metalexicográfica, como: termes de conversation/termes familiers/termes provinciaux/termes vulgaires/termes plébéiens/termes populaires et bas; termes nobles/termes propres au palais/termes propres à l'argot. 
sobrietas española, que en la visión de Doergang(k) contrasta con la voluptuosidad y la adicción al alcohol de los Germani, constituye la característica principal del modo de vivir español. Doergang( $(k)$ da un paso más, del comportamiento a la lengua: el español es una lengua "sagrada" (lingua sancta), en la cual se abarca la verdad y en la cual se afirma la gloria de Dios.

Hispani, Itali, \& Galli summo odio prosequuntur ebrietatem [...] Sed Hispani in primis, nam illi solent Gallos vocare borrachos, id est, ebriosos, quamvis tamen comparati cum Germanis sint sobriissimi [...] O Germania si in hac virtute sobrietatis Hispanos imitareris! [...] Stultissimi sunt qui putant Temulentos posse melius studere. [...]

Lingua Hispanica Sancta. Et in vera, syncera, aperta \& sancta Religione \& fide loquentur omnes gentes \& populi veram synceram, apertam \& sanctam linguam Hispanicam. Veram illam voco, quia Hispani veritatem amant \& maximè defendunt: Synceram \& apertam, quia syncero, recto \& aperto sunt corde Hispani. Et praeterea non est lingua apertior \& clarior, minusque tegumentis \& apostrophis involuta quàm Hispanica: nam omnes litterae in ea efferuntur, \& omnia clariora elementa ut sunt a, o, \& u, in ipsa dominantur: Sanctam nomino, quia quemadmodum lingua Hebraica vocatur sancta, quod populus Dei ea usa sit: Ita hanc iustissimè sanctam vocare possumus, quod eam is populus loquatur qui millies \& infinities magis causam Dei sine macula candidè defendunt, propagant, \& amplificant, quam unquam fecerit populus ludaicus, sive Hebraeus (Heinrich Doergang(k), Institutiones in linguam Hispa-

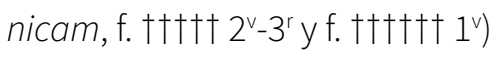

Mi segundo ejemplo viene del compendio (diccionario y gramática del español) que publicó, en 1659, el capellán de Amberes Arnaldo de la Porte. Si es verdad que el autor alaba la piedad de los habitantes de Amberes, se nota que la necesidad más urgente para él es la de resistir a la amenaza francesa y apoyar a la Corte madrileña.

Però bien puede assegurarse Su Magestad Catolica, que sus Flamencos no se dexaran lleuar al embustero sonido de aquellas Sirenes Machiauelistas, pues sus Leones Belgicos en tantas ocasiones prouocados, combatidos, y prouados, debaxo del Amparo Poderosissimo de Su Magestad no se atemorizan al canto del Gallo. Digo, que nuestros, no menos Esforçados que Inexpugnables Compatriotas (a cuya tan constante Lealdad y Amor con su Rey, al Respeto y Veneracion con sus Magistrados, a su Noble y Generoso procedimiento entre tantas difficultades por la defensa de su Patria, que oy admiran los ambos Polos, se deuen muchas Coronas y Tropheos) conocen muy bien que los Franceses no se siruen de tantos artificios, sino como de redes para pescar lo que pretende su ambicion; y lo echan de ver con tanta mayor euidencia, quanto mas son alumbrados de tantos Faros de Cordura y de luyzios rectos, que resplandecen en W.SS. (Arnaldo de la Porte, Nuevo Dictionario, o Thesoro De la lengua Española y Flamenca; Sale aora corregido y añadido de vna Grammatica Española, muy prouechosa para los que quieren perfectamente aprender la Lengua Castellana, 1659, f. 2v) 


\section{Ideologías lingüísticas: formación, mecanismos y unidades de- scriptivas}

Las ideologías pueden formarse de distintas maneras.

(I) Puede darse que su formación se haga de repente por una imposición y/o estipulación por parte de un individuo o de un grupo. Conocemos casos tanto en la historia de la filosofía como en la de las ciencias, como la "duda metódica" introducida como método filosófico por Descartes, o el criterio de cientificidad propuesto en el manifiesto neopositivista del círculo de Viena. Cabe observar que estos dos casos tuvieron su reflejo en la historia de la lingüística, con la corriente metódica en la gramaticografía francesa (y europea) en el siglo XVII (v. Swiggers, 1984) ${ }^{29}$, y con la inserción de la lingüística bloomfieldiana en el programa neopositivista (Bloomfield, 1939; v. Hiż y Swiggers, 1990).

(II) Al revés, hay ideologías que se forman a larga duración, de manera casi imperceptible, por "acostumbramiento", lo que no excluye aspectos de modificación (y fenómenos de discontinuidad). Aquí se puede hablar de formación "natural” y paulatina de ideologías. Un ejemplo posible sería la evolución del reconocimiento de propiedades específicas de lenguas hacia una ideología de la individualidad, del genio de la lengua ${ }^{30}$.

Me parece que hay que distinguir otros dos tipos.

(III) Uno es el tipo de formación "reaccionaria” (o subversiva), formación por la cual una ideología se crea para combatir (y sustituir a) otra existente: como ejemplo, se puede mencionar la corriente de la lingüística "idealista" ${ }^{1}$, que se concibió en reacción a la lingüística de los neogramáticos.

(IV) Por fin, otro tipo de formación es la formación por "exaptación" (ingl. exaptation), es decir una formación por especificación y priorización de ciertos principios de una ideología pre-existente; así, a partir del historicismo romántico, se puso rumbo, bajo la influencia de ciencias como la geología, hacia el 'uniformitarianismo' lingüístico (v. Christy, 1983).

29. Véase el Apéndice 2 para una lista de gramáticas del francés que se tildaron de "metódicas”.

30. Acerca del concepto de "genio de la lengua" (que tiene sus raices en la teoría antigua de la proprietas linguarum; v. Denecker 2017), véanse los estudios de Gensini (2003), Schlaps (2004) y Van Hal (2013), así como Hassler y Neiss (2009, s.v. "besonderer Character einer Sprache”). Sobre el (culto del) "genio de la lengua francesa”, v. Siouffi (2010). Lesser (2005) ofrece una antología de reflexiones por autores literarios.

31. La reacción idealista contra la lingüística de los neogramáticos se inspiró en las ideas de Benedetto Croce. Los trabajos fundamentales de la corriente idealista son los de Karl Vossler (por ejemplo 1904, 1925). Para un estudio historiográfico, véase Christmann (1985). 
En cuanto a los mecanismos de elaboración de ideologías, estos son todos mecanismos de (seudo-) justificación y conllevan una dimensión retórica importante. Me parece que se pueden reconocer por lo menos cinco mecanismos fundamentales:

a) diferenciación con valoracion (recomendación vs. descalificación)

b) simplificación o supresión de matizaciones

c) intento de racionalización

d) un mecanismo de "acomodación", que consiste en presentar el contenido ideológico como evidente, como casi natural

e) desplazamiento asociativo, por un proceso connotativo: la connotación, o transposición asociati$\mathrm{va}^{32}$, es un componente esencial de ideologías que conllevan una valoración. En el caso de las ideologías lingüísticas, se puede tratar de una connotación entre lo lingüístico y lo social, o socioculturali33, entre lo lingüístico y lo político, entre lo lingüístico y lo étnico, entre lo lingüístico y lo económico, entre lo lingüístico y lo geográfico (v. la división de Jean-Jacques Rousseau entre lenguas del norte y lenguas del sur).

Aunque no es fácil abarcar la articulación concreta de ideologías, se pueden identificar ciertos contenidos más o menos circunscritos (y codificados), y si queremos llamar a estos contenidos "unidades de descripción", los podríamos tildar de "ideologemas" (v. Swiggers, 2010). A través de la historia de la lingüística y de las praxis filosófico-lingüísticas destacan algunos ideologemas, como por ejemplo:

a) el ideologema de la lengua primitiva (ya presente en la Biblia), y su reinterpretación a través de los siglos ${ }^{34}$

b) el ideologema de la lengua perfecta (y universal), estudiado de manera pormenorizada por Eco $(1993)^{35}$;

c) el ideologema de la lengua pura o del dialecto puro; cabe insistir con respecto a esto que la propia distinción entre lengua y dialecto nunca ha estado exenta de coloración ideológica36;

d) el ideologema de la lengua clara y transparente; este ideologema tiene una presencia secular en la

32. Gal e Irvine (1995) hablan de iconicidad y de recursividad: estos dos aspectos son fundamentales para la connotación, porque ésta se basa en una reproducción de una similitud parcial.

33. En la literatura sociolingüística se habla de social connotation hypothesis; v. Trudgill y Giles (1978), Giles y Niedzielski (1998); para una aplicación a la historia de la lingüística, véase Denecker (2015).

34. Se trata de una temática muy cargada por razones religiosas, culturales y étnicas; v. Olender (1989).

35. Para un suplemento de información histórica y reflexiones metodológicas, véanse Droixhe (1997) y Swiggers (2001).

36. La distinción entre lengua y dialecto es una distinción histórica e ideológicamente cargada: confluyen aquí dados objetivos, factores culturales y valoraciones subjetivas. Sobre los orígenes lejanos y la elaboración de la distinción en la Edad Moderna, véase el estudio detallado de Van Rooy (2017). Acerca de los estereotipos en la formulación de la distinción, véase Van Hal y Van Rooy (2017). 
aproximación del francés (v. Swiggers, 2010b);

e) el ideologema de la lengua "purificada" (vs. variedades menos cultas)

f) el ideologema de una lengua neutra, exenta de prejuicios, de discriminaciones.

\section{Una agenda de investigación para historiadores de la lingüística}

Las ideologías lingüísticas examinadas por lingüistas, antropólogos y sociólogos suelen en general concernir a actitudes y comportamientos de hablantes, a políticas lingüísticas (oficiales o no), y a estrategias comunicativas por parte de hablantes y por parte de personas que están implicadas en uno u otro tipo de labor lingüística.

Se trata de un campo de estudios en plena evolución y muy prometedor, como lo observan Woolard y Schieffelin:

The topic of language ideology is a much-needed bridge between linguistic and social theory, because it relates the microculture of communicative action to political economic considerations of power and social inequality, confronting macrosocial constraints on language behavior. [...] It is also a potential means of deepening a sometimes superficial understanding of linguistic form and its cultural variability in political economic studies of discourse (Woolard y Schieffelin, 1994: 72)

A research focus on language ideology makes a promising bridge between linguistic and social theory. In spite of the traditional difficulties posed by the ideology concept, it allows us to relate the microculture of communicative action to political economic considerations of power and social inequality, to confront macrosocial constraints on language behavior, and to connect discourse with lived experiences [...] populations around the world posit fundamental linkages among such apparently diverse cultural categories as language, spelling, grammar, and nation, gender, simplicity, intentionality, authenticity, knowledge, development, power, tradition (Woolard, 1998: 27).

Queda claro que la investigación de ideologías lingüísticas necesita una agenda de investigación detallada. Tomando en cuenta que el público de las "Primeras Jornadas de Ideologías en obras sobre la lengua española” se compone esencialmente de historiadores de la lingüística (española), me parece útil esbozar una agenda con particular orientación historiográfica.

En primer lugar, cabe preguntarse si, más allá de la labor historiográfica, es posible inscribir las investigaciones sobre ideología(s) lingüística(s) dentro de un marco más amplio. Con respecto a esta pregunta, me parece interesante considerar la oportunidad de insertarlas dentro de, o por lo menos conectarlas con, el marco de la ecología lingüística, tal como fue definida por Einar Haugen (1970). En la concepción de Haugen, la ecología del lenguaje o ecología de lenguas (o ecología lingüística) reúne un conjunto de disciplinas, cuyas temáticas son las siguientes, con respecto a una (o más) lengua(s) examinada(s): 
(1) su relación con otras lenguas

(2) los hablantes de la lengua: el número, las clases sociales y los conocimientos lingüísticos de sus hablantes

(3) su vitalidad

(4) su "espacio comunicativo"

(5) sus variedades regionales (y su diversidad social)

(6) presencia de una literatura y de una tradición escrita

(7) el grado de estandarización

(8) el apoyo "institucional” del que puede gozar la lengua

(9) las actitudes y los sentimientos de los hablantes con respecto a la lengua.

La labor historiográfica sobre ideologías podrá aportar una documentación, y alimentar la discusión sobre varios aspectos del conjunto de disciplinas que constituyen la ecología lingüística.

En lo que se refiere a las tareas de la agenda de investigación, se pueden distinguir tres distintos tipos de enfoques:

(A) Un enfoque textual (para- y metatextual): aquí cabe colocar la investigación sobre la ideología lingüística que se refleja en los para-textos (prefacios, posfacios, textos añadidos, notas, comentarios) ${ }^{37}$, y sobre la ideología que se manifiesta en los ejemplos (ejemplos de gramáticas, de diccionarios) ${ }^{38}$.

El trabajo de investigación implicará un análisis de las fuentes, del grado de autoridad invocada, del nivel de lengua de los ejemplos, etc.). Dentro del componente metatextual, se sitúa el estudio de los aspectos ideológicos que están conectados con la terminología empleada (términos calificativos: marcas de uso ${ }^{39}$; glotonimia; elementos de innovación terminológica).

37. Sobre la importancia de los paratextos como documentos ideológicos, véanse Collinot (1985), Leiner (1990) y Calhoun (2017). De particular interés (para la "ideología nacional") son los prefacios de los diccionarios y de las gramáticas publicados por las academias nacionales; v. Quemada (1997) y Gómez Asencio (2011).

38. Para un estudio de los ejemplos en las primeras gramáticas de las lenguas vernáculas de Europa, véase Kistereva (2015).

39. Acerca de la aproximación terminológica e historiográfica de las marcas de uso en la producción lexicográfica, véanse los trabajos de Hausmann (1989) y Glatigny (1998). 
Como herramientas para este tipo de estudio, se destacan el análisis discursivo, la teoría argumentativa, y la lexicología socio-psicológico-política de Georges Matoréun. (palabras testigo + palabras clave)

(B) Un enfoque instrumental: a este nivel cabe situar la ideología implicada en aspectos de comparación de lenguas (por ejemplo ¿qué variedades se utilizan en una gramática comparativa de las “lenguas románicas"?), y aspectos de la utilización de técnicas de análisis, de descripción y de representación ${ }^{41}$.

(C) Un enfoque teórico: aquí se colocan estudios de ideología lingüística que toman como objeto de investigación los contenidos (y más en particular, la valoración "axiológica” de esos contenidos) ${ }^{42}$ de las teorías.

\section{Ideología(s) de la lingüística}

La lengua que se habla tiene un extenso trasfondo ideológico; las actitudes y actividades emprendidas con respecto a la lengua también están marcadas por posicionamientos ideológicos. Las cosas no son diferentes cuando miramos la lingüística -a pesar de la creencia cándida en la 'neutralidad' de la ciencia-. Aparte del hecho de que la lingüística puede ser criticada desde un punto de vista (neo)marxista como construcción teórica ${ }^{43}$, hay ideología(s) de la lingüística: desde los inicios de la lingüística como ciencia con denominación propia, su evolución ha sido caracterizada por tensiones y oposiciones de naturaleza ideológica. Bastará mencionar las tensiones entre filología (clásica) y lingüística comparativa (v. Koerner, 1982; Swiggers, 1998), la oposición entre la lingüística de tipo neogramático y la lingüística "naturalista" (v. Desmet, 1996), la reacción de la escuela (neo)idealista contra la lingüística de los neogramáticos, la crítica del estructuralismo con respecto a la lingüística tradicional e histórica, las oposiciones entre escuelas estructuralistas y posestructuralistas en los Estados Unidos (v. Murray, 1994), o las luchas entre modelos dentro del generativismo (v. Harris, 1993).

El estudio de tales tensiones y oposiciones pertenece al terreno de la filosofía (lógica y metodología) y la sociología de las ciencias. Los aspectos ideológicos forman una parte esencial de la investi-

40. Matoré (1953) propuso una metodología de lexicología socio-histórica basada en el estudio de periodos político-económicos y con orientación a la psicología colectiva; una herramienta fundamental de su metodología son las palabras testigo (fr. mots-témoins), reveladoras de la situación (material y espiritual) de una sociedad), y las palabras clave (fr. mots-clés), que captan la esencia de una época. En los años 1980 aplicó esta metodología al estudio del léxico francés medieval y del siglo XVI (Matoré 1985, 1988).

41. Con "representación" (o: notación), me refiero al aspecto de uso de diagramas, de imágenes, de graphs, etc. (v. Roggenbuck, 2005, Mazziotta, 2016).

42. En el análisis de esos contenidos se atiende a la argumentación de teorías y a convicciones o asunciones ideológicas subyacentes; v. los trabajos de Botha $(1970,1971,1973)$ y los estudios recogidos en Koerner (1975) acerca del modelo transformacional.

43. Véanse los trabajos de Rossi-Landi $(1973,1977)$. 
gación que se debe hacer, y para esto habrá que indagar las estrategias retóricas ${ }^{44}$ y los mecanismos de desfiguración ${ }^{45}$ de las teorías opuestas.

Para una comprensión adecuada de la complejidad del "relleno" ideológico de teorías lingüísticas, me parece muy relevante una distinción introducida por Herman Parret (1979) en su libro Filosofie en taalwetenschap (= "Filosofía y lingüística"): se trata de la distinción entre ideología esencial e ideologías co-ocurrentes. Partiendo de la asociación muy frecuentemente establecida entre el posestructuralismo y un cierto "antihumanismo", y, por el otro lado, entre el generativismo de Chomsky y un (nuevo) humanismo, Parret demuestra que tal asociación no se justifica: en el posestructuralismo se observan varios aspectos "humanistas", por ejemplo en la atención acordada a la expresividad (por ejemplo, en la estilística), o a la intersubjetividad e intertextualidad (temas de la sociolingüística y del análisis del discurso), y, al revés, el (auto)proclamado "humanismo" del modelo generativista opera con nociones abstractas, más o menos deshumanizadas (ideas innatas; algoritmos de reglas, "gramática internalizada" o l-grammar)".

Por esa razón, Parret, básandose en la teoría de Greimas (1976), introduce la distinción entre "ideología esencial" e "ideologías co-ocurrentes": la ideología esencial no es otra cosa que la praxis discursiva que realmente fundamenta una teoría/un modelo y el quehacer de los que utilizan el modelo. Se observa entonces que el modelo generativista conlleva, en su esencia, una ideología (casi neopositivista) de "formalismo", de "aproximación internalista" del lenguaje, y de argumentación fundada en los principios estipulativos de la propia teoría.

Ideologías co-ocurrentes son las que los propios productores de modelos o el público receptor pueden relacionar, a su gusto, con una teoría. La relación con la teoría ya no es una relación lógico-analítica, sino una relación contingente; y a veces puede suceder que una ideología co-ocurrente presente una contradicción, más o menos explícita, con la ideología esencial de la misma teoría. El terreno de las ideologías co-ocurrentes es un terreno que se abre a toda forma de estrategias retóricas, por las cuales productores y/o receptores apuntan rasgos posiblemente muy llamativos de una teoría. Y al mismo tiempo estas estrategias se acompañan de ataques contra teorías opuestas ${ }^{47}$.

44. Batista (2015) ofrece un estudio socio-retórico de la discusión entre formalistas y funcionalistas en la lingüística brasileña de finales del siglo XX.

45. Un ejemplo asombroso de desfiguración es la crítica por Noam Chomsky del libro Verbal Behavior de Skinner, como si este hubiera contenido una teoría de la adquisición de una lengua; v. MacCorquodale (1970) y Swiggers (1997a).

46. Según Parret, queda claro que el propio Chomsky, a partir de mediados de los años 1960, ha esbozado una ideología 'humanista' como "envoltura" de su teoría lingüística; al mismo tiempo ha mantenido un discurso muy crítico en el cual confundió, sin matizar, corrientes como empirismo, positivismo y behaviorismo.

47. Me parece que la distinción entre ideología esencial e ideología(s) co-ocurrentes debería combinarse con la distinción entre niveles de teorización dentro de un modelo teórico: teoría del lenguaje, teoría de la gramática, teoría de la lingüística; cf. Garvin (1979) y Swiggers (1983). 


\section{Concluyendo con Borges: el impacto ideológico del tiempo}

La cuestión fundamental que cabe plantear es la siguiente: ¿es posible escapar de la ideología, de una influencia ideológica?

Es bien sabido que la solución platónica con respecto a la tentación y al embrujamiento por la doxa, era la de una pura contemplación de las ideas: pero, ¿no es otra ideología la de creer en tal aproximación pura, inmaculada, de la verdad? Es por lo menos lo que un escéptico objetaría.

La filosofía de autores como Jürgen Habermas (por ejemplo, 1973) o Michel Foucault (por ejemplo, 1969) insiste justamente sobre la presencia inevitable de ideologías (v. ya Mannheim 1953): el acto de querer distanciarse (o de pensar poder hacerlo) de toda forma de ideología sería por definición un gesto fundamentalmente ideológico. Y, como lo hemos subrayado, la convicción de una ciencia "neutra", que consistiría únicamente en enunciados intersubjetivamente controlables y abiertos a la "verificación/falsificación", no es otra cosa sino una posición que no se puede demostrary establecer de manera absolutamente objetiva; es, pues... otra posición ideológica.

Pero, más allá de la no inocencia de las teorías lingüísticas -y, en consecuencia, de la no neutralidad de los lingüistas-, hay otra realidad innegable, y que no se puede poner fuera de juego: es la de la función ideológica del tiempo. Y con esto quiero decir que el mero fenómeno del transcurso histórico es el motor de incidencias ideológicas, y de cambios ideológicos. Bastaría reproducir el texto de una gramática del siglo XVI o XVII y tomarlo como testimonio gramatical de nuestra época para darse cuenta de cómo el tiempo instaura una coloración ideológica.

Este papel ideológico del tiempo, nadie lo ha ilustrado mejor, y de manera incomparable, como Jorge Luis Borges en su historia de Pierre Menard, texto publicado por primera vez en 1941 (y recogido en el libro Ficciones, 1944). Borges (o el "narrador" de esta breve "ficción") nos cuenta el proyecto48 de Menard:

No quería componer otro Quijote - lo cual es fácil - sino el Quijote. Inútil agregar que no encaró nunca una transcripción mecánica del original; no se proponía copiarlo. Su admirable ambición era producir unas páginas que coincidieran -palabra por palabra y línea por líneacon las de Miguel de Cervantes.

48. Un proyecto del cual el propio Menard se había hecho una idea precisa: "El método inicial que imaginó era relativa-
mente sencillo. Conocer bien el español, recuperar la fe católica, guerrear contra los moros o contra el turco, olvidar la
historia de Europa entre los años de 1602 y de 1918 , ser Miguel de Cervantes. Pierre Menard estudió ese procedimiento
(sé que logró un manejo bastante fiel del español del siglo diecisiete) pero lo descartó por fácil. jMás bien por imposible!
dirá el lector. De acuerdo, pero la empresa era de antemano imposible y de todos los medios imposibles para llevarla
a término, éste era el menos interesante. Ser en el siglo veinte un novelista popular del siglo diecisiete le pareció una
disminución. Ser, de alguna manera, Cervantes y llegar al Quijote le pareció menos arduo-por consiguiente, menos inte-
resante- que seguir siendo Pierre Menard y llegar al Quijote, a través de las experiencias de Pierre Menard” (Borges, 1994). 
"Mi propósito es meramente asombroso", me escribió el 30 de septiembre de 1934 desde Bayonne. "El término final de una demostración teológica o metafísica - el mundo externo, Dios, la causalidad, las formas universales - no es menos anterior y común que mi divulgada novela. La sola diferencia es que los filósofos publican en agradables volúmenes las etapas intermediarias de su labor y que yo he resuelto perderlas". (Borges, 1944)

Menard llevó a cabo su proyecto, por lo menos, bajo forma de un texto (imuy!) parcial, y Borges nos comenta, secamente, el resultado:

El texto de Cervantes y el de Menard son verbalmente idénticos, pero el segundo es casi infinitamente más rico. (Más ambiguo, dirán sus detractores; pero la ambigüedad es una riqueza.)

Es una revelación cotejar el Don Quijote de Menard con el de Cervantes. Éste, por ejemplo, escribió (Don Quijote, primera parte, noveno capítulo):... la verdad, cuya madre es la historia, émula del tiempo, depósito de las acciones, testigo de lo pasado, ejemplo y aviso de lo presente, advertencia de lo porvenir.

Redactada en el siglo diecisiete, redactada por el "ingenio lego" Cervantes, esa enumeración es un mero elogio retórico de la historia. Menard, en cambio, escribe: ... la verdad, cuya madre es la historia, émula del tiempo, depósito de las acciones, testigo de lo pasado, ejemplo y aviso de lo presente, advertencia de lo porvenir. La historia, madre de la verdad; la idea es asombrosa. Menard, contemporáneo de William James, no define la historia como una indagación de la realidad sino como su origen. La verdad histórica, para él, no es lo que sucedió; es lo que juzgamos que sucedió. Las cláusulas finales -ejemplo y aviso de lo presente, advertencia de lo porvenir-son descaradamente pragmáticas.

También es vívido el contraste de los estilos. El estilo arcaizante de Menard -extranjero al finadolece de alguna afectación. No así el del precursor, que maneja con desenfado el español corriente de su época. (Borges, 1944)

A través de este lúdico ensayo, transparece una verdad universal: todo acto discursivo lleva la huella de su contexto de producción, y querer negarlo - o querer borrar la impresión de esta huella - es una manipulación. Hemos dicho: manipulación. ¿Esa no es precisamente una estrategia esencial de las ideologías? Así volvemos a la cuestión inicial: ¿hay manera de escapar de las ideologías o -utilizando una imagen de Wittgenstein (1953: § 309)- somos como la mosca cogida en la botella de la(s) ideología(s)? La pregunta queda, y quedará, abierta... 


\section{Bibliografía}

Asad, Talal (1979), "Anthropology and the Analysis of Ideology", Man, n 14, p. 607-627.

Batista, Ronaldo de Oliveira (2015), "Retórica de ruptura e descontinuidades nas ciências da linguagem: um estudo pela Historiografia da Linguística”, Confluência, n 49, p. 119-141.

Bauman, Richard y Sherzer, Joel (eds.) (1974), Explorations in the Ethnography of Speaking, Cambridge, Cambridge University Press.

Bloomfield, Leonard (1944), "Secondary and Tertiary Responses to Language", Language, n²0, p. 44-55.

Bloomfield, Leonard (1927), "Literate and Illiterate Speech". American Speech, n² 2, p. 432-439.

Bloomfield, Leonard (1939), Linguistic Aspects of Science, Chicago, University of Chicago Press.

Borges, Jorge Luis (1944), Ficciones, Buenos Aires, Editorial Sur.

Borsche, Tilman (1981), Sprachansichten. Der Begriff der menschlichen Rede in der Sprachphilosophie Wilhelm von Humboldts, Stuttgart, Klett-Cotta.

Botha, Rudolf P. (1970), The Methodological Status of Grammatical Argumentation, The Hague, Mouton.

Botha, Rudolf P. (1971), Methodological Aspects of Transformational Generative Phonology, The Hague, Mouton.

Botha, Rudolf P. (1973), The Justification of Linguistic Hypotheses: a study of nondemonstrative inference in transformational grammar, The Hague, Mouton.

Bursill-Hall, Geoffrey L. (1971), Speculative Grammars of the Middle Ages, The Hague, Mouton.

Calhoun, Doyle (2017), "Reading Paratexts in Missionary Linguistic Works: An analysis of the preface to the Holy Ghost Fathers' (1855) Dictionnaire français-wolof et wolof-français”, Language \& History, $n^{\circ}$ 60, p. 53-72.

Christmann, Hans Helmut (1985), Filología idealista y lingüística moderna, Madrid, Gredos.

Christy, Craig (1983), Uniformitarianism in Linguistics, Amsterdam/Philadelphia, Benjamins.

Collinot, André (1985), "L’ouverture des dictionnaires : remarques sur les titres et préfaces des dictionnaires français du XVII siècle", Lexique, n³ 3, p. 11-27.

Cruz Casáñez, María y Swiggers, Pierre (2015), “La gramática anónima de Lovaina de 1559: contribución al hispanismo en Flandes”, en Eulalia Hernández Sánchez y María Isabel López Martínez (eds.), Sodalicia Dona, Murcia, Universidad de Murcia, Servicio de Publicaciones, p. 109-123.

Denecker, Tim (2015), "Language attitudes and Social Connotations in Jerome and Sidonius Apollinaris", Vigiliae Christianae, n 69, p. 393-421. 
Denecker, Tim (2017), Ideas on Language in Early Latin Christianity. From Tertullian to Isidore of Seville, Leiden/Boston, Brill.

Derbolav, Josef (1972), Platons Sprachphilosophie im 'Kratylos' und in den späteren Schriften, Darmstadt, Wissenschaftliche Buchgesellschaft.

Desmet, Piet (1996), La linguistique naturaliste en France (1867-1922): nature, origine et évolution du langage, Leuven, Peeters.

Desmet, Piet, Rooryck, Johan, y Swiggers, Pierre (1990), "What are Words Worth? Language and ideology in French dictionaries of the revolutionary period”, en John E. Joseph y Talbot J. Taylor (eds.), Ideologies of language, p. 162-188.

Droixhe, Daniel (1978), La linguistique et l'appel de l'histoire, Genève, Droz.

Droixhe, Daniel (1997), "Réflexions sur quelques pages d'Umberto Eco: La ricerca della lingua perfetta", en Pierangiolo Berrettoni y Franco Lorenzi (eds.), Grammatica e ideologia nella storia della linguistica, Perugia, Margiacchi-Galeno, p. 281-292.

Eagleton, Terry (1991), Ideology: An Introduction, London, Verso.

Eco, Umberto (1993), La búsqueda de la lengua perfecta en la cultura europea, Barcelona, Crítica.

Errington, Joseph J. (1988), Structure and Style in Javanese: A Semiotic View of Linguistic Etiquette, Philadelphia, University of Pennsylvania Press.

Errington, Joseph J. (2007), Linguistics in a Colonial World: a Story of Language, Meaning, and Power, New York, Blackwell.

Esparza Torres, Miguel Ángel (2005), "Los prólogos de Alonso Molina (1510-1585): destrucción de una ideología", Península: revista de estudios ibéricos, n² 2, p. 69-91.

Esparza Torres, Miguel Ángel (2014), "La 'lengua de los vencidos' y 'nuestra lengua’: de nuevo en torno al ideario de la lingüística misionera”, Boletín hispánico helvético, nº 23, p. 273-294.

Esparza Torres, Miguel Ángel (2015), "On the Linguistic Ideas Underlying the Work of 16th-Century Mesoamerican Missionaries", Historiographia Linguistica, n 42, p. 211-231.

Esparza Torres, Miguel Ángel (2016), "Elogio de la lengua nativa y planteamiento metalingüístico en las gramáticas misioneras: el ejemplo de Domingo de Santo Tomás", Revista de investigación Lingüística, no 19, p. 15-33.

Fabian, Johannes (1986), Language and Colonial Power: The Appropriation of Swahili in the Former Belgian Congo 1880-1938, Cambridge, Cambridge University Press.

Flaitz, Jeffra (1988), The Ideology of English: French Perceptions of English as a World Language, Berlin, Mouton de Gruyter.

Foucault, Michel (1969), L’Archéologie du savoir, Paris, Gallimard. 
Friedrich, Paul (1989), "Language, Ideology and Political Economy", American Anthropologist, n 91, p. 295-312.

Gal, Susan (1989), "Language and Political Economy", Annual Review of Anthropology, no 18, p. 345367.

Gal, Susan (1993), "Diversity and Contestation in Linguistic Ideologies: German Speakers in Hungary", Pragmatics, n 5, p. 155-166.

Gal, Susan e Irvine, Judith T. (1995), "The Boundaries of Languages and Disciplines: How Ideologies Construct Difference", Social Research, n 62, p. 967-1001.

Gal, Susan y Woolard, Kathryn A. (1995), "Constructing Languages and Publics: Authority and Representation", Pragmatics, no 5, p. 129-138.

Garvin, Paul L. (1979), "Une épistémologie empiriste pour la linguistique”, La Linguistique, nº 15, p. 65-89.

Geertz, Clifford (1973), "Ideology as a Cultural System", en Clifford Geertz, The Interpretation of Cultures, New York, Basic Books, p. 193-233.

Gensini, Stefano (2003), "Per la storia di 'ingegno': un termine chiave del lessico intellettuale europeo", en Hans-Ingo Radatz y Raimund Schlösser (eds.), Donum Grammaticorum. Festschrift für Harro Stammerjohann, Tübingen, Niemeyer, p. 87-101.

Gerighausen, Josef (1963), Die historische Deutung der Nationalsprache im französischen Schrifttum des 16. Jahrhunderts, Bonn, Friedrich-Wilhelms-Universität.

Giles, Howard y Niedzielski, Nancy (1998), "Italian is Beautiful, German is Ugly", en Laurie Bauer y PeterTrudgill (eds.), Language Myths, London, Duckworth, p. 85-93.

Glatigny, Michel (1998), Les marques d'usage dans les dictionnaires français monolingues du XIXe siècle, Tübingen, Niemeyer.

Gómez Asencio, José J. (2011), Los principios de las gramáticas académicas (1771-1962), Bern, Peter Lang.

Greimas, Algirdas J. (1976), Sémiotique et sciences sociales, Paris, Seuil.

Gumperz, John (ed.) (1982), Language and Social Identity, Cambridge, Cambridge University Press.

Gumperz, John e Hymes, Dell H. (eds.) (1972), Directions in Sociolinguistics: The Ethnography of Communication, New York, Holt.

Habermas, Jürgen (1973), La technique et la science comme “Idéologie”, Paris, Gallimard.

Harris, Randy Allen (1993), The Linguistics Wars, New York, Oxford University Press. 
Hassler, Gerda (2011), "Identität durch Sprache. Der Diskurs zur Apologie der Vernakularsprachen bis zum 18. Jahrhundert”, en Cornelia Klettke y Ralf Pröve (eds.), Brennpunkte kultureller Begegnungen auf dem Weg zu einem modernen Europa, Göttingen, Vandenhoeck \& Ruprecht, p. 47-69.

Hassler, Gerda y Neis, Cordula (2009), Lexikon sprachtheoretischer Grundbegriffe des 17. und 18. Jahrhunderts, Berlin, de Gruyter.

Haugen, Einar (1970), The Ecology of Language, Stanford, Stanford University Press.

Hausmann, Franz Josef (1989), "Die Markierung im allgemeinen einsprachigen Wörterbuch: eine Übersicht", en Rufus Gouws, Ulrich Heid, Wolfgang Schweickard, Herbert Ernst Wiegand (eds.), Dictionaries/Dictionnaires/Wörterbücher, Berlin/New York, de Gruyter, vol. I, p. 649-657.

Hiż, Henry y Swiggers, Pierre (1990), "Bloomfield, the Logical Positivist”, Semiotica, n 79, p. 257-270.

Hymes, Dell H. (1974), Foundations in Sociolinguistics, Philadelphia, University of Pennsylvania Press.

Irvine, Judith T. (1989), "When Talk isn't Cheap: Language and Political Economy”, American Ethnologist, $n^{\circ} 16$, p. 248-267.

Joseph, John E. (1987), Eloquence and Power: The Rise of Language Standards and Standard Languages, New York, Blackwell.

Joseph, John E. y Taylor, Talbot J. (eds.) (1990), Ideologies of Language, New York, Routledge.

Juliard, Pierre (1970), Philosophies of Language in Eighteenth Century France, The Hague, Mouton.

Kistereva, Maria (2015), L'exemple dans les grammaires de l'Europe occidentale des XVe et XVIe siècles, Tesis de doctorado, Bruselas, Université libre de Bruxelles.

Koerner, E.F. Konrad (ed.) (1975), The Transformational-Generative Paradigm and Modern Linguistic Theory, Amsterdam, Benjamins.

Koerner, Konrad (1982), "On the historical roots of the philology/linguistics controversy", en Anders Ahlqvist (ed.), Papers from the 5th international conference on historical linguistics, Amsterdam, Benjamins, p. 404-413.

Kroskrity, Paul V. (1992), "Arizona Tewa Public Announcements: Form, Function, Linguistic Ideology", Anthropological Linguistics, n³4, p. 104-116.

Kroskrity, Paul V. (2000), "Regimenting Language", en Kroskrity (ed.), Regimes of Language. Ideologies, Polities, and Identities, Santa Fé, School of American Research Press, p. 1-34.

Kroskrity, Paul V. (ed.) (2000), Regimes of Language. Ideologies, Polities, and Identities, Santa Fé, School of American Research Press.

Kroskrity, Paul V. (2004), "Language Ideologies", en Alessandro Duranti (ed.), Companion to Linguistic Anthropology, Malden, B. Blackwell, p. 496-517.

Larrain, Jorge (1979), The Concept of Ideology, Athens, University of Georgia Press. 
Leiner, Wolfgang (1990), “Préface à la journée des préfaces", Cahiers de l'Association internationale des études françaises, nº 42, p. 111-119.

Lesser, Wendy (ed.) (2005), The Genius of Language. Fifteen writers reflect on their mother tongue, New York, Anchor.

MacCorquodale, Kenneth (1970), "On Chomsky's Review of Skinner's Verbal Behavior", Journal of the Experimental Analysis of Behavior, n 13, p. 83-99.

Mannheim, Karl (1953), Ideology and Utopia, New York, Harcourt Brace Jovanovich. [Título original: Ideologie und Utopie, 1929. Traducción y notas de Louis Wirth y Edward Shils.]

Matoré, Georges (1953), La méthode en lexicologie: domaine français, Paris, Didier.

Matoré, Georges (1985), Le vocabulaire et la société médiévale, Paris, P.U.F.

Matoré, Georges (1988), Le vocabulaire et la société du XV/e siècle, Paris, P.U.F.

Mazziotta, Nicolas (2016), "Drawing syntax before syntactic trees: Stephen Watkins Clark's sentence diagrams (1847)", Historiographia Linguistica, n 43, p. 301-342.

McQuown, Norman (1984), "El lenguaje en la cultura y en la sociedad y en la personalidad", Cuadernos de Estudios Lingüísticos, nº 6, p. 95-110.

Milroy, James y Milroy, Leslie (1985), Authority in Language: Investigating Language Prescription and Standardization, London, Routledge \& Kegan Paul.

Murray, Stephen O. (1994), Theory Groups and the Study of Language in North America. A social history, Amsterdam, John Benjamins.

Olender, Maurice (1989), Les langues du Paradis, Paris, Gallimard.

Parret, Herman (1979), Filosofie en taalwetenschap, Assen, van Gorcum.

Picot, Émile (1906-1907), Les Français italianisants au XVIe siècle, Paris, Champion.

Quemada, Bernard (ed.) (1997), Les préfaces du Dictionnaire de l'Académie française: 1694-1992, Paris, Champion.

Roggenbuck, Simone (2005), Die Wiederkehr der Bilder: Arboreszenz und Raster in der interdisziplinären Geschichte der Sprachwissenschaft, Tübingen, Narr.

Rosier, Irène (1983), La grammaire spéculative des modistes, Lille, Presses universitaires de Lille.

Rossi-Landi, Ferruccio (1973), Ideologies of Linguistic Relativity, The Hague, Mouton.

Rossi-Landi, Ferruccio (1977), Linguistics and Economics, The Hague, Mouton.

Schieffelin, Bambi, Woolard, Kathryn A. y Kroskrity, Paul V. (eds.) (1998), Language Ideologies. Practice and Theory, New York/Oxford, Oxford University Press. 
Schlaps, Christiane (2004), "The 'Genius of Language’”, Historiographia Linguistica, n’31, p. 367-388.

Silverstein, Michael (1979), "Language Structure and Linguistic Ideology", en Paul R. Clyne, William F. Hanks y Carol L. Hofbauer (eds.), The Elements: Parasession on units and levels, Chicago, Chicago Linguistics Society, p. 193-248.

Silverstein, Michael (1985), "Language and the Culture of Gender: At the Intersection of Structure, Usage and Ideology", en Elizabeth Mertz y Richard J. Parmentier (eds.), Semiotic Mediation, Orlando, Academic Press, p. 319-359.

Siouffi, Gilles (2010), Le génie de la langue française, Paris, Champion.

Sozzi, Lionello (1972), "La polémique anti-italienne en France au XVle siècle", Atti dell'Accademia delle Scienze di Torino, n 106, p. 99-190.

Swiggers, Pierre (1983), "Qu'est-ce qu'une théorie (en) linguistique?", Modèles Linguistiques, n 5, p. 3-15.

Swiggers, Pierre (1984), "La méthode dans la grammaire française du dix-septième siècle", en Pierre Swiggers (ed.), Grammaire et méthode au XVIIe siècle, Leuven/Paris, Peeters, p. 9-34.

Swiggers, Pierre (1997a), "Ideology in Linguistic Debate: Chomsky's Critique of Skinner's Verbal Behavior", en Pierangiolo Berrettoni y Franco Lorenzi (eds.), Grammatica e ideologia nella storia della linguistica, Perugia, Margiacchi-Galeno, p. 257-279.

Swiggers, Pierre (1997b), "Français, italien (et espagnol): un concours de 'précellence' chez Henri Estienne”, en Gunter Holtus, Johannes Kramer y Wolfgang Schweickard (eds.), Italica et Romanica: Festschrift für Max Pfister zum 65. Geburtstag vol. II, Tübingen, Max Niemeyer, p. 297-311.

Swiggers, Pierre (1997c), "Grammaire et lexicographie françaises à l'époque de la Révolution", en Bernd Spillner (ed.), Französische Sprache in Deutschland im Zeitalter der französischen Revolution, Zürich/Frankfurt am Main, Peter Lang \& Europäischer Verlag der Wissenschaften, p. 169-192.

Swiggers, Pierre (1998), "Filologia e lingüística: enlace, divórcio, reconciliação", Filologia e Lingüística Portuguesa, n 2, p. 5-18.

Swiggers, Pierre (2001), "L'idée de langue universelle et de langue parfaite dans l'histoire de la linguistique occidentale", en Giovanna Massariello Merzagora (ed.), Storia del pensiero linguistico: linearità, fratture e circolarità, 13-44. Roma, Il Calamo, p. 13-44.

Swiggers, Pierre (2003), "Henri Estienne et le 'français italianisé': un témoignage écolinguistique du XVle siècle", en Hans-Ingo Radatz y Raimund Schlösser (eds.), Donum Grammaticorum. Festschrift für Harro Stammerjohann, Tübingen, Niemeyer, p. 303-314.

Swiggers, Pierre (2009), "Le français et l'italien en lice: l'examen comparatif de leurs qualités chez Henri Estienne", Synergies Italie, n5, p. 69-76. 
Swiggers, Pierre (2010a), "Les enjeux de l'enseignement des langues aux Temps Modernes: dimensions ludique, politique et idéologique de la didactique et de la didaxologie", en Javier Suso López (ed.), Plurilinguisme et enseignement des langues en Europe: aspects historiques, didactiques et sociolinguistiques, Granada: Editorial Univ. de Granada, p. 79-123.

Swiggers, Pierre (2010b), “La clarté du français: examen d’un 'idéologème’”, Zeitschrift für romanische Philologie, n²126, p. 443-459.

Swiggers, Pierre (2011), "La lexicografía francesa de la época revolucionaria”, en Félix San Vicente, Cecilio Garriga y Hugo E. Lombardini (eds.), Ideolex. Estudios de Lexicografía e Ideología, Monza, Polimetrica International Scientific Publisher, p. 347-360.

Swiggers, Pierre (2017), "Intuition, Exploration, and Assertion of the Indo-European language relationships", en Jared Klein, Brian Joseph y Matthias Fritz (eds.), Handbook of Comparative and Historical Indo-European Linguistics vol. I, Berlin/New York, De Gruyter Mouton, p. 138-170.

Trudeau, Danielle (1992), Les inventeurs du bon usage (1529-1647), Paris, Éd. de Minuit.

Trudgill, Peter y Giles, Howard (1978), "Sociolinguistics and Linguistic Value Judgements: Correctness, Adequacy, and Aesthetics”, en Frank Coppieters y Didier L. Goyvaerts (eds.), Functional Studies in Language and Literature, Gent: Story-Scientia, p. 167-190.

Van Hal, Toon (2010), Moedertalen en taalmoeders: Het vroegmoderne taalvergelijkende onderzoek in de Lage Landen, Brussel, KNAW.

Van Hal, Toon (2013), "Génie de la langue’: the genesis and early evolution of a key notion in Early Modern European learning", Language and History, n 56, p. 81-97.

Van Hal, Toon y Van Rooy, Raf (2017), “'Differing only in Dialect', or How Collocations can co-shape Concepts”, Language \& Communication, n56, p. 95-109.

Van Rooy, Raf (2017), Through the vast labyrinth of languages and dialects. The emergence and transformations of a conceptual pair in the early modern period (ca. 1478-1782), tesis de doctorado, Leuven, Katholieke Universiteit te Leuven.

Véron, Eliseo (1978), "Sémiosis de l’idéologie et du pouvoir", Communication, n 28, p. 7-20.

Vossler, Karl (1904), Positivismus und Idealismus in der Sprachwissenschaft, Heidelberg, Carl Winter.

Vossler, Karl (1925), Geist und Kultur in der Sprache, Heidelberg, Carl Winter.

Wittgenstein, Ludwig (1953), Philosophical Investigations, ed. por Gertrud Elizabeth M. Anscombe y Rush Rhees, Oxford, B. Blackwell.

Woolard, Kathryn A. (1998), "Introduction: Language Ideology as a Field of Inquiry", en Schieffelin, Woolard y Kroskrity (eds.) (1998), p. 3-47.

Woolard, Kathryn A. y Schieffelin, Bambi (1994), "Language Ideology”, Annual Review of Anthropology, $n^{\circ} 23$, p. 55-82. 


\section{Apéndices}

\section{Apéndice 1: Textos de alabanza a la lengua nacional en el siglo XVI}

1535. Juan de Valdés, Diálogo de la lengua [manuscrito, editado en 1737 por Mayans y Siscar, Diálogo de las lenguas]

1540. João de Barros, Diálogo em louvor da nossa linguagem, Lisboa.

1542. Sperone Speroni, Dialogo delle lingue, Venecia.

1549. Joachim du Bellay, La Deffence, et Illustration de la Langue francoyse, Paris.

1572. Guilielmus Rabottus, Oratio de gente et lingua Francica, Wittenberg.

1574. Martín de Viziana [Viçiana], Libro de alabanças de las lenguas hebrea, griega, latina, castellana yvalenciana, Valencia.

1574. Pedro Magalhães de Gândavo, Diálogo em defensão da língua portuguesa, Lisboa.

1579. Henri Estienne, De la Precellence de la langue françoise, Paris.

1586. Simon Stevin, Uytspraeck van de weerdigheyt der duytsche taele, Leiden.

1589. Jacob Rybinski, De linguae Polonicae praestantia et utilitate, Toruń.

1595-6. Richard Carew, Epistle on the Excellency of the English Tongue [manuscrito, en el British Museum; impr. 1614]

1617. Martin Opitz, Aristarchus, sive De contemptu linguae Teutonicae, Beuthen a/d Oder. 


\section{Apéndice 2: Gramáticas "metódicas" del francés publicadas en la segunda mitad del siglo XVII}

1656. Claude Irson. Nouvelle methode pour apprendre facilement les principes et la pureté de la langue françoise [...]. Paris.

1658. Jean-Marie Filz. Nouvelle methode ou abbregé de la grammaire et de la Rethorique [...]. Paris. [Ed. en 1669: Methode courte et facile pour apprendre les langues latine et françoise [...]. Paris.]

1663. Guido Fanois. Methodus accurata linguae Gallicae principia, praxim et puritatem docens. Lugduni Batavorum.

1664. [S.] Telles. Gallicae Linguae grammatica, Singulari Methodo à S. Tellaeo conscripta, Praecipuê in eorum gratiam qui linguam Germanicam Callent. Grammaire Françoise, Par le Sieur Telles, Professeur en la Langue \& Mathematique Françoise. Strasbourg.

1666. Franciscus de Fenne. Libri tres compendii Grammaticae Gallicae, In usum maximè Tyronum clarâ ac facili methodo conscripti à Francisco de Fenne. Gotha.

1666. Alexander Joli. Metode Nouvelle et très-utile, pour apprendre parfaitement \& en peu de tems, la Langue Françoise [...]. Hambourg.

1674. François d'Aisy. Nouvelle Methode de la Langue françoise: Divisée en quatre Parties. Paris.

1679. Joannes Elledurt. Methodus curiosa variis referta observationibus a Joanne Elledurt. Holm.

1680. Jean Menudier. Le secret d'apprendre la langue françoise en riant. [...] avec une nouvelle Methode, Pour apprendre facilement la Langue Françoise, Deux tables, qui servent de Grammaire, \& un indice des regles \& des remarques. Frankfurt/Leipzig.

1681. Denis Vairasse d'Allais. Grammaire methodique contenant en abregé les principes de cet art et les Regles les plus necessaires de la Langue Françoise dans un ordre clair \& naturel. Paris.

1683. Jean Meyer. Le Maître de Langue Muet, ou instruction methodique pour apprendre de soy même les principes de la Langue Françoise [...]. Nürnberg.

1684. Isidoro Lanfredini. Nuovo metodo facile, e breve Per imparar la Lingua Francese. Firenze.

1687. Ruau. La vraye methode d'enseigner la langue Françoise aux etrangers. Paris.

1689. Jean-Robert des Pepliers. Grammaire royale françoise \& allemande contenant une Methode nouvelle \& facile pour apprendre en peu de temps la langue françoise [...]. Berlin. 
1694. Abel Boyer. The Compleat French-Master, for Ladies and Gentlemen, Being A New Method, to Learn with ease and delight the French Tongue, as it is now spoken in the Court of France. London.

1694. Pierre Marin. Nouvelle methode pour apprendre les principes et l'usage des langues françoise et hollandoise. Amsterdam.

1697. David Janssaeus. La veritable clef de la langue françoise, ou abregé metodique de la grammaire françoise. Ratzeburg.

1699. L. Charbonnet. Les principes de la langue Françoise ou grammaire methodique pour l'usage de la jeunesse. Halle. 